\title{
SUMBER DAYA DALAM MANAJEMEN ASFIKSIA PADA RUMAH SAKIT PENYELENGGARA PELAYANAN OBSTETRI NEONATAL EMERGENSI KOMPREHENSIF DI KABUPATEN DEMAK
}

\author{
Resources of Asphyxia Management on Regional Public Hospital Providing Obstetric and \\ Neonatal Emergency Comprehensive Care in Demak Regency
}

\author{
Siti Nurjanah \\ Universitas Muhammadiyah Semarang \\ Email: shalmadenayu@yahoo.com
}

\begin{abstract}
ABSTRAK
Data yang diperoleh dari RSUD Kabupaten Demak tahun 2014 menunjukkan bahwa asfiksia merupakan penyebab kematian perinatal yang paling tinggi. Pada tahun 2014 terdapat 14 (10,6) kematian perinatal akibat asfiksia dari 132 kasus asfiksia, tahun 2013 terdapat 12 (6,03) kematian perinatal dari 199 kasus asfiksia, dan tahun 2012 terdapat 15 (6,41) kematian perinatal dari 234 kasus asfiksia. Penelitian ini bertujuan untuk mengetahui pengaruh sumber daya terhadap implementasi manajemen asfiksia di Pelayanan Obstetri Neonatal Emergensi Komprehensif (PONEK) RSUD Sunan Kalijaga Demak. Jenis penelitian ini adalah deskriptif kualitatif. Informan utama pada penelitian ini adalah 3 orang bidan/perawat di PONEK, dan Informan triangulasi yaitu Wakil Ketua Tim PONEK, Bidan Koordinator, dan ibu dengan bayi asfiksia. Hasil penelitian menunjukkan bahwa dalam pelaksanaan manajemen asfiksia sumber daya manusia masih kurang, belum semua petugas mendapatkan pelatihan PONEK. Sarana prasarana, jarak antar ruang antara UGD, VK, ruang Perinatal, dan bangsal kebidanan letaknya masih berjauhan dan tidak tersedianya ruang khusus untuk manajemen asfiksia dan masih ada alat yang rusak. Disimpulkan bahwa kekurangan dalam pelaksanaan manajemen asfiksia di Rumah Sakit Penyelenggara PONEK berkaitan dengan ketersediaan Sumber Daya. Disarankan agar pihak Rumah Sakit meningkatkan kesempatan untuk mengikuti pelatihan PONEK.
\end{abstract}

Kata kunci : Implementasi, sumber daya, manajemen asfiksia, PONEK

\section{ABSTRACT}

Data obtained from Demak Regional Public Hospital 2014 showed asphyxia was the most high that cause of perinatal mortality. In 201414 (10.6) perinatal death of 132 cases of asphyxia, 2013 there were 12 (6.03) perinatal mortality of 199 cases of asphyxia, and 2012 there were 15 (6.41) perinatal deaths of 234 cases of asphyxia. The research aims to determine the effect of the resources towards the implementation of the management of Neonatal asphyxia in Obstetric Service Comprehensive civil defence emergency (PONEK) Sunan Kalijaga Hospital. This type of research was qualitative, descriptive. The main informant on this study was 3 persons a midwife/nurse in PONEK, the informant and triangulation that was Vice Chairman Tim PONEK, Coordinator, and the mother with the baby asphyxiation. The results showed that in the implementation of human resources management of asphyxia was still lacking, not all officers received training PONEK. Infrastructure, the distance between the spaces between the ER, VK, Perinatal, obstetrics wards and its location are still far apart and the unavailability of special spaces for management of asphyxia and there is still a broken tool. It was concluded that the deficiencies in the implementation of the management of asphyxia in hospital Organizers PONEK relates to the availability of resources. It is recommended that the hospital increases chance PONEK training to follow.

Keywords: Implementation, resources, management of asphyxia, PONEK

\section{PENDAHULUAN}

Angka Kematian Ibu (AKI) dan Angka Kematian Bayi (AKB) merupakan salah satu indikator pembangunan kesehatan dalam RPJMN 2015-2019 dan SDGs. Menurut data SDKI, AKB mengalami penurunan dari tahun ke tahun yaitu pada SDKI 2012 menunjukan angka 32/1.000 KH (SDKI 2012). Pada tahun 2015, berdasarkan data SUPAS 2015 AKB menunjukan penurunan menjadi 22,23/ 1000 $\mathrm{KH})$ yang artinya sudah mencapai target MDG's 2015 sebesar 23 per 1.000 kelahiran hidup. (Profil Kesehatan Indonesia, 2016)

AKB di Provinsi Jawa Tengah tahun 2016 sebesar 99,9 per 1.000 kelahiran hidup, sama dengan AKB tahun 2015. Kabupaten/kota dengan AKB terendah adalah Kota Surakarta yaitu 3,36 per 1.000 kelahiran hidup, diikuti Jepara (5,46 per 1.000 kelahiran 
hidup) dan Demak (5,86 per 1.000 kelahiran hidup). Peningkatan akses dan kualitas pelayanan bagi bayi baru lahir (neonatal) menjadi prioritas utama di Indonesia. Hal ini karena kematian neonatal (0-28 hari) memberi kontribusi terhadap 59\% kematian bayi. Angka kematian neonatal di Jawa Tengah tahun 2016 sebesar 6,94 per 1.000 kelahiran hidup. AKN paling rendah adalah Kota Surakarta 1,43 per 1.000 kelahiran hidup, diikuti Demak $(4,22$ per 1.000 kelahiran hidup) dan Jepara $(4,27$ per 1.000 kelahiran hidup) (Profil Kesehatan Jawa Tengah, 2016).

Berdasarkan data kementerian kesehatan diketahui bahwa sebesar 46,2\% kematian bayi disebabkan oleh masalah neonatal yaitu asfiksia dan BBLR (Yuwono SR, 2014). Asfiksia merupakan penyebab kematian neonatal yang paling tinggi. Penyebab kematian tersebut dapat dicegah dan ditangani jika masyarakat dengan mudah dapat mengakses pelayanan kesehatan, memiliki tenaga kesehatan yang kompeten, sistem rujukan yang berjalan dengan baik, deteksi dini dan kesadaran orang tua untuk mencari pertolongan kesehatan.

Dinas Kesehatan Kabupaten Demak telah mencapai target Renstra Kementerian Kesehatan dalam hal fasilitas pelayanan kesehatan mampu PONED dan PONEK, dimana terdapat 6 (enam) Puskesmas mampu PONED dan 1 (satu) Rumah Sakit mampu PONEK. Rumah sakit yang telah mampu PONED di Kabupaten Demak adalah Rumah Sakit Umum Daerah Sunan Kalijaga.

Berdasarkan data yang diperoleh dari RSUD Kabupaten Demak tahun 2014 menunjukkan bahwa asfiksia merupakan penyebab kematian perinatal paling tinggi. Pada tahun 2014 terdapat $14(10,6)$ kematian perinatal akibat asfiksia dari 132 kasus asfiksia, tahun 2013 terdapat $12 \quad(6,03)$ kematian perinatal dari 199 kasus asfiksia, dan tahun 2012 terdapat $15(6,41)$ kematian perinatal dari 234 kasus asfiksia.

Melihat masih adanya beberapa kasus asfiksia yang berujung kematian perlu adanya analisis pelaksanaan implementasi manajemen askfikisa berdasarkan teori implementasi Edward yang menyatakan bahwa salah satu faktor terpenting dari yaitu sumber daya.

\section{METODE PENELITIAN}

Penelitian ini merupakan penelitian deskriptif kualitatif bertujuan untuk menggali informasi lebih mendalam atau untuk mendapatkan penjelasan secara terperinci tentang suatu fenomena atau masalah. Pengumpulan data dalam penelitian ini dilakukan dengan wawancara mendalam dan observasi, dimana pelaksanaanya dilakukan hanya satu kali saja pada saat yang sama atau pengumpulan data dilakukan sekaligus pada suatu saat (one shoot) (Sugiyono, 2014). Subyek penelitian dipilih dengan menggunakan metode purposive sampling. Informan utama dalam penelitian ini dipilih dari anggota tim PONEK Rumah Sakit Umum Daerah Demak yang terdiri dari, bidan dan perawat pelaksana. Informan triangulasi dalam penelitian ini adalah Penanggungjawab tim PONEK, Ketua tim PONEK, dan Ibu yang memiliki bayi asfiksia.

\section{HASIL DAN PEMBAHASAN}

RSUD Sunan Kalijaga selalu berbenah untuk memberikan layanan kesehatan yang terbaik kepada masyarakat. Saat ini RSUD Sunan Kalijaga Demak memiliki sumber daya manusia (SDM) dokter utama sebanyak 53 dokter. Dari 53 dokter itu, 30 di antaranya adalah spesialis. Adapun tenaga dukung medis di RSUD Sunan Kalijaga Demak adalah berjumlah 527 orang.

Berdasarkan Surat Keputusan Direktur RSUD Sunan Kalijaga Demak No. 700/1106/2012 jumlah tim PONEK terdiri dari 7 orang yaitu 1 ketua, 1 wakil, dan 5 anggota. Inhouse Training untuk untuk tim PONEK dilakukan setiap 1 tahun sekali diantaranya adalah IMD, Penanganan Kegawatdaruraratan Maternal Noeonatal namun belum semua SDM di PONEK mendapatkan pelatihan tersebut. Sarana prasarana untuk kebutuhan PONEK sudah ada namun ada alat yang masih rusak. 


\section{Gambaran Karakteristik Informan Informan Utama Penelitian}

Informan utama dalam penelitian berjumlah 3 (tiga) orang yang merupakan anggota tim PONEK RSUD Sunan Kalijaga Demak. Karakteristik informan utama sebagaimana terlihat pada Tabel 1 .

Tabel 1 Karakteristik informan utama perawat dan bidan

\begin{tabular}{lccc}
\hline Kode & $\begin{array}{c}\text { Umur } \\
\text { (Thn) }\end{array}$ & Pendidikan & Jabatan \\
\hline IU1 & 46 & $\begin{array}{c}\text { D3 } \\
\text { Kebidanan }\end{array}$ & $\begin{array}{c}\text { Staf R. } \\
\text { Melati }\end{array}$ \\
\hline IU2 & 34 & S1 & $\begin{array}{c}\text { Perawat } \\
\text { Kelaksana } \\
\end{array}$ \\
& & Keperawata & Pelaks \\
\hline IU3 & 33 & D3 & $\begin{array}{c}\text { Bidan } \\
\text { Pelaksana } \\
\text { UGD }\end{array}$ \\
& & &
\end{tabular}

Tabel 1 di atas menunjukkan bahwa informan utama dalam penelitian ini rata-rata memiliki umur $>30$ tahun dan sudah memiliki pendidikan minimal D3 Kebidanan.

\section{Informan Triangulasi}

Informan triangulasi di dalam penelitian ini, yaitu : Wakil Ketua Tim PONEK (ITTP), Bidan Koordinator (ITBK) dengan karakteristik sebagai berikut:

Tabel 2 Karakteristik Informan Triangulasi :

Wakil Ketua Tim PONEK (ITTP) dan Bidan Koordinator (ITBK)

\begin{tabular}{cccc}
\hline Kode & $\begin{array}{c}\text { Umur } \\
(\text { Thn })\end{array}$ & Pendidikan & $\begin{array}{c}\text { Kasa } \\
\text { Kerja } \\
(\text { Thn })\end{array}$ \\
\hline ITTP & 51 & Spesialis Anak & 9 \\
\hline ITBK & 47 & D4 Kebidanan & 28 \\
\hline
\end{tabular}

Tabel 2 menunjukkan bahwa informan triangulasi rata-rata memiliki umur $\geq 47$ tahun, memiliki pendidikan terakhir minimal
D4 Kebidanan dan memiliki masa kerja antara 9-28 tahun. Informan triangulasi peneliti selanjutnya, yaitu ibu dengan bayi askfisia dengan karakteristik sebagai berikut:

Tabel 3 Karakteristik Informan Triangulasi Ibu dengan bayi asfiksi

\begin{tabular}{cccc}
\hline Kode & $\begin{array}{c}\text { Umur } \\
(\text { Thn })\end{array}$ & Pendidikan & Pekerjaan \\
\hline ITIB & 26 & SMA & Ibu \\
& & & $\begin{array}{c}\text { Rumah } \\
\text { Tangga }\end{array}$ \\
\hline
\end{tabular}

Tabel 3 menunjukkan bahwa informan triangulasi dari ibu bayi memiliki umur 26 tahun dan berpendidikan terakhir Sekolah Menengah Atas (SMA), serta bekerja sebagai ibu rumah tangga (IRT).

\section{Sumber daya \\ Sumber daya manusia}

Sumber daya manusia merupakan salah satu sumber daya yang terdapat dalam organisasi, meliputi semua orang yang melakukan aktivitas. Sumber daya manusia merupakan satu - satunya sumber daya yang memiliki akal, perasaan, keinginan, kemampuan, ketrampilan, dorongan, daya dan karya. Semua potensi sumber daya tersebut sangat berpengaruh terhadap upaya organisasi dalam pencapaian tujuan. Dalam pengantar adminstrasi Kesehatan, tenaga yang memadahi memiliki beberapa manfaat seperti tercapainya tujuan dengan memuaskan, memungkinkan efektifitas dan efisiensi kerja, dan menambah gairah bekerja, begitu pula sebaliknya (Dwidjowijoto, 2013).

Berdasarkan kesimpulan dari seluruh informan utama dan informan triangulasi didapatkan peran dan fungsi tim PONEK dalam pelaksanaan manajemen asfiksi sudah bekerja sesuai dengan wewenang masingmasing, selain itu dari tim PONEK juga sudah memberikan pelatihan kepada SDM.

Hasil wawancara mendalam mengenai kemampuan dan ketrampilan petugas sudah cukup tetapi perlu ditingkatkan dengan pelatihan-pelatihan lain apabila ada ilmu yang baru. Selama berkomitmen menjadi RS PONEK baru ada 4orang dari tim PONEK yang telah mengikuti pelatihan. Bagi tim 
PONEK yang belum mendapatkan pelatihan asfiksi maka dari pihak tim PONEK akan melakukan pelatihan bergilir yang akan dimentori oleh SDM yang mendapatkan pelatihan dari luar Rumah Sakit. Biasanya yang mengikuti pelatihan di luar adalah dokter atau kepala ruang. Upaya-upaya yang dilakukan untuk mencapai kompetensi yaitu pelatihan, pembinaan internal dokter obsgin dengan bidan, in house training, AMP, dan audit medik untuk Komite Medik. Pelatihan guna mendukung kinerja tim PONEK sangat dibutuhkan. Menurut buku pedoman PONEK, dokter dan perawat harus terlatih dalam asuhan neonatal meliputi pemberian ASI, resusitasi neonatus, dan kegawatdaruratan neonatus (Buku Acuan Manajemen Asfiksia Bayi Baru Lahir Untuk Bidan, 2010).

Kotak 1

"Kita kalau pelatihan eksternal itu biasanya hanya ketua ruangan saja yang mengikuti nanti ilmunya di beritahuhan atau di ajarkan kepada yang laennya seperti itu yang saya tahu" (IU1)

"Untuk pelatihan ya seperti pelatihan yang kemaren itu ya, tetapi kalau ada pelatihan dari luar biasanya yang ikut hanyaperwakilan saja nanti kita beritahukan ke teman-teman lainya seperti dilakukan pelatihan seperti kemarin"”, (ITBK)

Hasil ini sama dengan hasil penelitihan Permadi (2014) yang diperoleh belum semua anggota tim PONEK mendapatkan pelatihan. Berdasarkan buku pedoman PONEK seharusnya semua tim PONEK diberangkatkan pelatihan, sehingga dalam satu tim semua mempunyai kemampuan yang sama dalam penanganan kasus kegawatdaruratan khususnya penanganan manajemen asfiksi (Buku Acuan Manajemen Asfiksia Bayi Baru Lahir Untuk Bidan, 2010).

Jumlah tenaga untuk manajemen asfiksi masih kurang menurut seluruh informan. Untuk kecukupan pendidikan dan pelatihan sudah cukup namun harus selalu mengembangkan ketrampilan melalui pelatihan-pelatihan apabila ada ilmu baru. Sampai saat ini hambatan hanya ada pada jumlah SDM yang kurang tetapi tidak menggangu dalam proses pelaksanaan manajemen asfiksi.

Kotak 2

“... hambatanya tenaganya terbatas itu tadi” (IU1)

“... tenaga juga masih terbatas" (IU3)

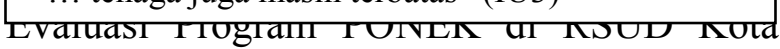

Semarang dimana sumber daya manusia secara kuantitas masih kurang mencukupi. Tidak jauh berbeda dengan penelitian Margaret (2012) tentang Status Darurat Perawatan obstetri di Area Pemerintah Daerah di Selatan Nigeria dengan hasil hanya 2 fasilitas $(16,67 \%)$ memiliki persyaratan minimum $\geq 4$ bidan untuk pelayanan kegawatdaruratan 24 jam.

Beberapa hasil penelitian sebelumnya diketahui bahwa pencapaian kriteria SDM PONEK bukanlah yang mudah, namun pemenuhan kebutuhan SDM tetap harus diperhatikan untuk keberhasilan program layanan PONEK khususnya pelaksanaan manajemen asfiksi. Berdasarkan penelitian yang dilakukan Simbolon (2013) menemukan bahwa sebanyak $477(69,6 \%)$ rumah sakit dengan sumber daya manusia tim PONEK tidak lengkap memiliki kinerja yang kurang optimal, begitu pula sebaliknya.49 Perlu ada penambahan SDM agar penganganan hasus manajemen asfiksi dapat dikerjakan secara full tim.

\section{Sarana prasarana}

Berdasarkan hasil wawancara menunjukkan bahwa ketersediaan sarana prasarana dalam pelaksanaan manajemen asfiksi belum optimal. Hasil observasi didapatkan bahwa jarak antar ruang antara UGD, VK, ruang Perinatal, dan bangsal kebidanan letaknya masih berjauhan. Terutama terkait dengan tidak tersedianya ruang khusus untuk manajemen asfiksi selain itu masih ditemukan adanya alat yang rusak. Hal tersebut tidak jauh berbeda dengan hasil penelitian Kusumawati (2012) dimana sarana prasarana PONEK belum memenuhi standar.

Kotak 3

“... ruang khusus tidak ada, ya ini ruang khusus untuk penatalaksanaan asfiksia resusitasi, bayi asfiksi masuk ke PERI" (IU2) 
Kotak 4

“...Untuk alat memang ada tetapi terkadang ada alat yang rusak seperti itu" (IU3)

Ketersediaan obat sudah cukup dalam pelaksanaan manajemen asfiksi. Ketersediaan semua obat-obatan selama ini sudah mencukupi kebutuhan, dalam kondisi baik dan siap digunakan. Hasil ini sebanding dengan penelitian Wulandari (2015) dimana obat sudah memenuhi standar.

Upaya dalam rangka menjaga mutu pada penyelenggaraan PONEK khususnya manajemen asfiksi harus memenuhi ruang tindakan gawat darurat dengan instrument dan bahan yang lengkap. Ketidaklengkapan sarana dan prasarana akan berdampak pada kualitas layanan yang diberikan. Sarana dan prasarana yang belum ada pada masingmasing indikator agar bisa segera dipenuhi, terutama ruang untuk manajemen asfiksi yang memerlukan perhatian khusus karena belum ada. Keberadaan sarana dan prasarana belum sesuai dengan pedoman dan masih ada alat yang rusak. Kondisi ini harus segera dilengkapi dan diperbaiki. Walaupun ada alat yang rusak tetapi manajemen asfiksi selama ini dapat ditangaini dengan baik, kondisi ini perlu dipertahankan.

\section{SIMPULAN}

Disimpulkan bahwa dalam pelaksanaan manajemen asfiksia di Rumah Sakit PONEK Kabupaten Demak masih ada kekurangan dalam hal kurangnya jumlah SDM terlatih dan tidak tersedianya ruang khusus PONEK. Disarankan bagi RS untuk menambah jumlah SDM terlatih PONEK dan dibuat ruangan yang terpusat untuk PONEK.

\section{DAFTAR PUSTAKA}

Dinas Kesehatan Provinsi Jawa Tengah. Profil Kesehatan Provinsi Jawa Tengah Tahun 2016. Semarang: Dinas Kesehatan Provinsi Jawa Tengah; 2017.
Dwidjowijoto RN. Analisis Kebijakan. Jakarta: PT Elex Media Komputindo; 2013.

Kementerian Kesehatan Republik Indonesia. . Buku Acuan Manajemen Asfiksia Bayi Baru Lahir Untuk Bidan. Jakarta: Bina Kesehatan Masyarakat Kementerian Kesehatan Republik Indonesia; 2010.

Kementerian Kesehatan Republik Indonesia. Profil Kesehatan Indonesia 2016. Jakarta: Kementerian Kesehatan Republik Indonesia; 2017.

Kementerian Kesehatan Republik Indonesia. Rencana Strategis Kementerian Kesehatan Tahun 2010-2014. Jakarta: Kementerian Kesehatan Republik Indonesia; 2010.

Kusumawati, Nur Indah. Evaluasi Program Pelayanan Obstetri dan Neonatal Emergncy Komprehensif (PONEK) di RSUD Kota Semaang 2012. Semarang: Universitas Diponegoro. Semarang; 2013.

Permadi, Dwi. Evaluasi tata cara penerimaan rujukan sebagai respon Pelayanan Obstetri dan Neonatal Emergensi Komprehensif (PONEK) di RSUD Kota Semarang. Semarang: Universitas Diponegoro. Semarang; 2014.

Wulandari, Shinta Dewi. Gambaran Pelaksanaan Pelayanan Obstetri Emergensi dan Kejadan Kematian Maternal di RSUD Tugurejo. Semarang: Universitas Muhammadiyah Semarang; 2016.

Yuwono SR. Kebijakan Kementerian Kesehatan Dalam Penurunan AKI \& AKB Dalam Konteks Pelayanan Klinik. Seminar Sehari Tentang Kepemimpinan Dokter Spesialis Obgyn dan Dokter Spesialis Anak dalam Penurunan Kematian Ibu dan Bayi. Yogyakarta; 2014. 